\title{
A Postprandial Plasma Glucose (PPG) Comparison Study between Pre-COVID-19 and During COVID-19 Using GH- Method: Math-Physical Medicine (No. 317)
}

\author{
Gerald C. Hsu \\ eclaireMD Foundation, USA.
}

*Corresponding Author: Gerald C. Hsu, eclaireMD Foundation, USA.

\begin{abstract}
The author utilizes quantitative analysis results based on diabetes control for two periods: the pre-COVID19 period, from 5/5/2018 to 1/18/2020, and the COVID-19 period, from 1/19/2020 to 8/24/2020, within a duration of 2.3 years. Special attention has been placed on his specific lifestyle management during the COVID19 quarantine period from 1/19/2020 to 8/24/2020.
\end{abstract}

The COVID-19 period has a lower average Finger PPG (-6 mg/dL) along with a lower sensor PPG (-12 mg/ $d L)$. By comparing these two periods, the two glucose waveforms are similar in shape (with high correlation coefficient) and the differences between these two curves at each time instant are quite close to each other (about $12 \mathrm{mg} / \mathrm{dL}$ glucose difference). As a result, during this period, the author achieved $0.3 \%$ to $0.4 \%$ lower HbA1C value.

COVID-19 is more than 100x worse compared to the fatal respiratory illness known as severe acute respiratory syndrome or SARS that occurred in 2003, in regard to its spreading speed, fatality number, and emotional impact on the world population. People belonging to the "vulnerable" groups, such as the elderly with existing chronic diseases and history of complications require special consideration to their health conditions and lifestyle management during the COVID-19 period.

However, during this period, the author collected better results with his diabetes control in terms of both PPG and HbA1C values. The knowledge and experience he acquired in the past 10 years of medical research and his developed mathematical metabolism index model along with four diabetes prediction tools assisted him in many ways. As a result, he achieved a reduction of $-6 \mathrm{mg} / \mathrm{dL}$ for finger $P P G,-12 \mathrm{mg} / \mathrm{dL}$ for sensor $P P G,-13$ $\mathrm{mg} / \mathrm{dL}$ for K-line PPG, and $-0.3 \%$ to $-0.4 \%$ for HbA1C. In fact, he turned the COVID-19 crisis into his health advantage!

\section{INTRODUCTION}

The author utilizes quantitative analysis results based on diabetes control for two periods: the pre-COVID-19 period, from 5/5/2018 to $1 / 18 / 2020$, and the COVID19 period, from $1 / 19 / 2020$ to $8 / 24 / 2020$, within a duration of 2.3 years. Special attention has been placed on his specific lifestyle management during the COVID-19 quarantine period from $1 / 19 / 2020$ to $8 / 24 / 2020$.

\section{METHODS}

\section{Background}

To learn more about the GH-Method: math-physical medicine (MPM) methodology, readers can review the article to understand his MPM analysis method in Reference 1, along with the outlined history of his personalized diabetes research and application tools development in Reference 2. 

Using GH-Method: Math-Physical Medicine (No. 317)

During 2015 and 2016, he dedicated his time to research four prediction models related to his diabetes measurement conditions such as weight, postprandial plasma glucose (PPG), fasting plasma glucose (FPG), and $\mathrm{HbA1C}(\mathrm{A} 1 \mathrm{C})$. As a result from using his own developed metabolism model and 4 prediction tools, by the end of 2016, his weight reduced from $220 \mathrm{lbs}$. (100 kg) to $176 \mathrm{lbs}$. (89 kg), waistline from 44 inches $(112 \mathrm{~cm})$ to 33 inches $(84 \mathrm{~cm})$, average finger glucose value from $280 \mathrm{mg} / \mathrm{dL}$ to $120 \mathrm{mg} / \mathrm{dL}$, and A1C from $10 \%$ to $\sim 6.5 \%$. One of his major accomplishments is that he no longer takes any diabetes medications since $12 / 8 / 2015$.

Around 1850, a Japanese merchant, who traded in the rice market in Osaka, Japan, started the "candlestick charting". An American, Steve Nison brought the candlestick concept to the Western world in 1991. These techniques are currently used in the stock market by financial analysts to predict the trend of stock prices and/or aid with the required action for the investment.

On $4 / 17 / 2018$, the author had an idea to study glucose behavior by using the candlestick chart as known as the "K-Line" and subsequently developed a customized software to analyze his big glucose data. These candlesticks not only provide 5 key characters of each daily glucoses but also reveal the average values and trends over a period of time when combined with the time-series analysis (References 6 \& 7).

During 2018 and 2019, the author traveled to 50+ international cities to attend $60+$ medical conferences and made $\sim 120$ oral presentations. This hectic schedule inflicted damage to his diabetes control, through dinning out along with exercise disruption, and on the overall metabolism status due to irregular life routines through traveling.

\section{COVID-19}

The author eluded the 2003 SARS in China and Taiwan. In early January 2020, when the rumors of a strange "Wuhan pneumonia" suddenly appeared on certain Asian news networks, he immediately recognized the danger associated with this newly found virus. The spread of this disease depends mainly on the physical contact among people. Therefore, he launched his "self-quarantine" in the
United States on $1 / 19 / 2020$, much earlier than the majority of Europeans and Americans who became aware of its potential damage and severity. As of today, $8 / 24 / 2020$, he has been self-quarantined for $7+$ months or 218 days. The timeframe of regular life pattern with home cooked meals and persistent walking exercise made his conditions on diabetes control (from his glucose results) reach to its "best" status for the past 25 years.

\section{Data Collection}

Since $1 / 1 / 2012$, the author measured his glucose values using the finger-piercing method: once for FPG and three times for PPG each day. On 5/5/2018, he applied a continuous glucose monitoring (CGM) sensor device on his upper arm and checked his glucose measurements every 15 minutes, a total of $\sim 80$ times each day. After the first bite of his meal, he assessed his PPG level every 15 minutes for a total of 3-hours or 180 minutes. He maintained the same measurement pattern from 5/5/2018 until present day.

\section{Epidemic Information}

COVID-19 is a disease caused by SARS-CoV-2 virus which uses ACE-2 for cell entry (Reference 3). The current thought is that the disease is spread through respiratory droplets, though the transmission is still under investigation. Also, the virus has been found in blood and stool. In Figure 1, it shows that COVID19 is a spectrum of diseases. Approximately $80 \%$ of confirmed cases are uncomplicated SARS-CoV-2 infection that may lead to mild pneumonia. About $15 \%$ would lead into severe pneumonia, with the remaining $5 \%$ ending up as acute respiratory distress syndrome (ARDS).

In Figure 2, it depicts confirmed cases and number of deaths in the USA since its inception until now, $8 / 24 / 2020$. This figure contains both curves in real case number and percentages. The confirmed percentage is defined as confirmed cases divided by total population of USA, while the death percentage is defined as death number divided by total confirmed cases. It is obviously that, COVID-19 is still not under control in the US; therefore, the author is mentally prepared that he will continue the existing selfquarantined life until the end of 2020 or perhaps even longer. 
A Postprandial Plasma Glucose (PPG) Comparison Study between Pre-COVID-19 and During COVID-19 Using GH-Method: Math-Physical Medicine (No. 317)

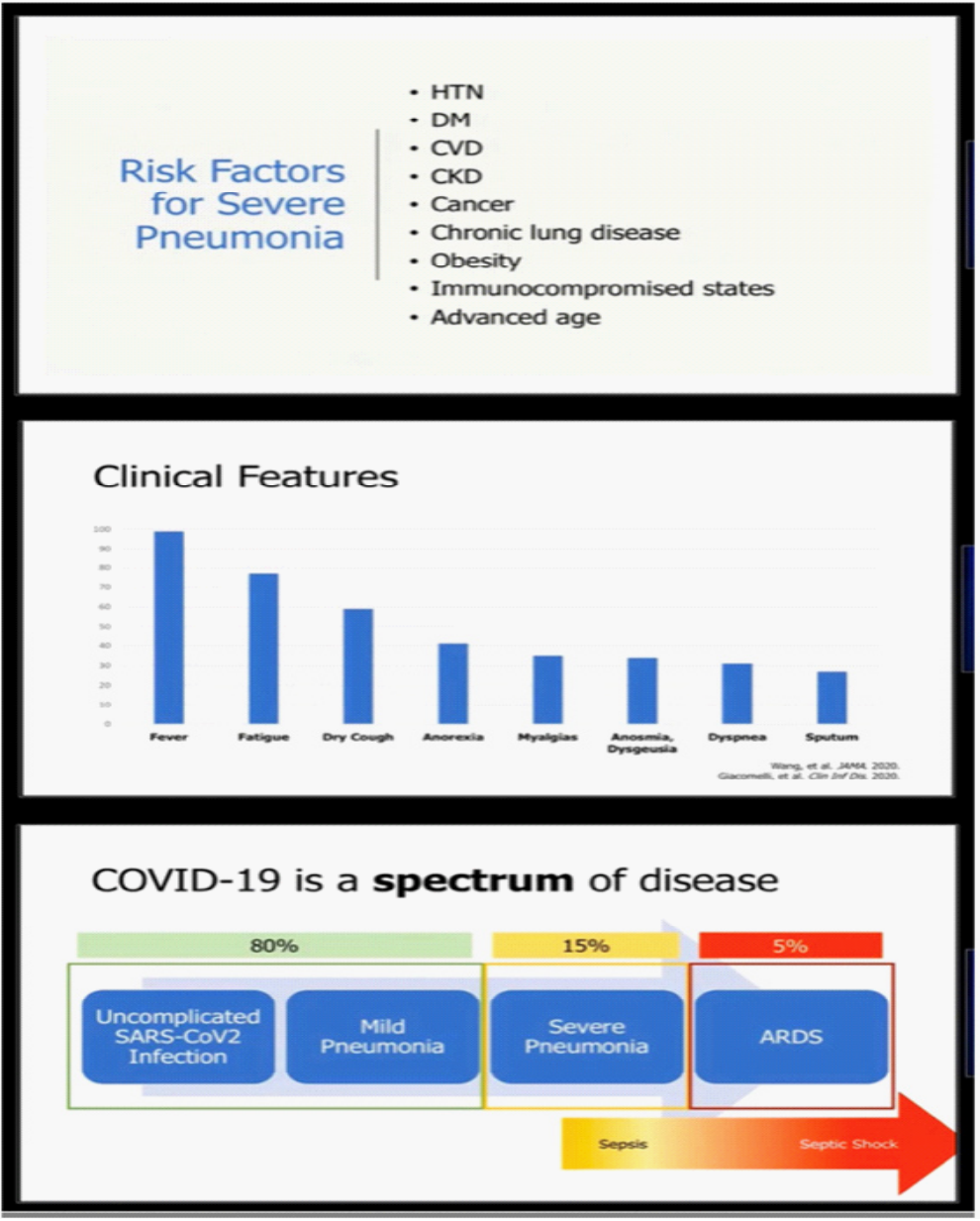

Fig1. COVID-19 information (Reference 3)

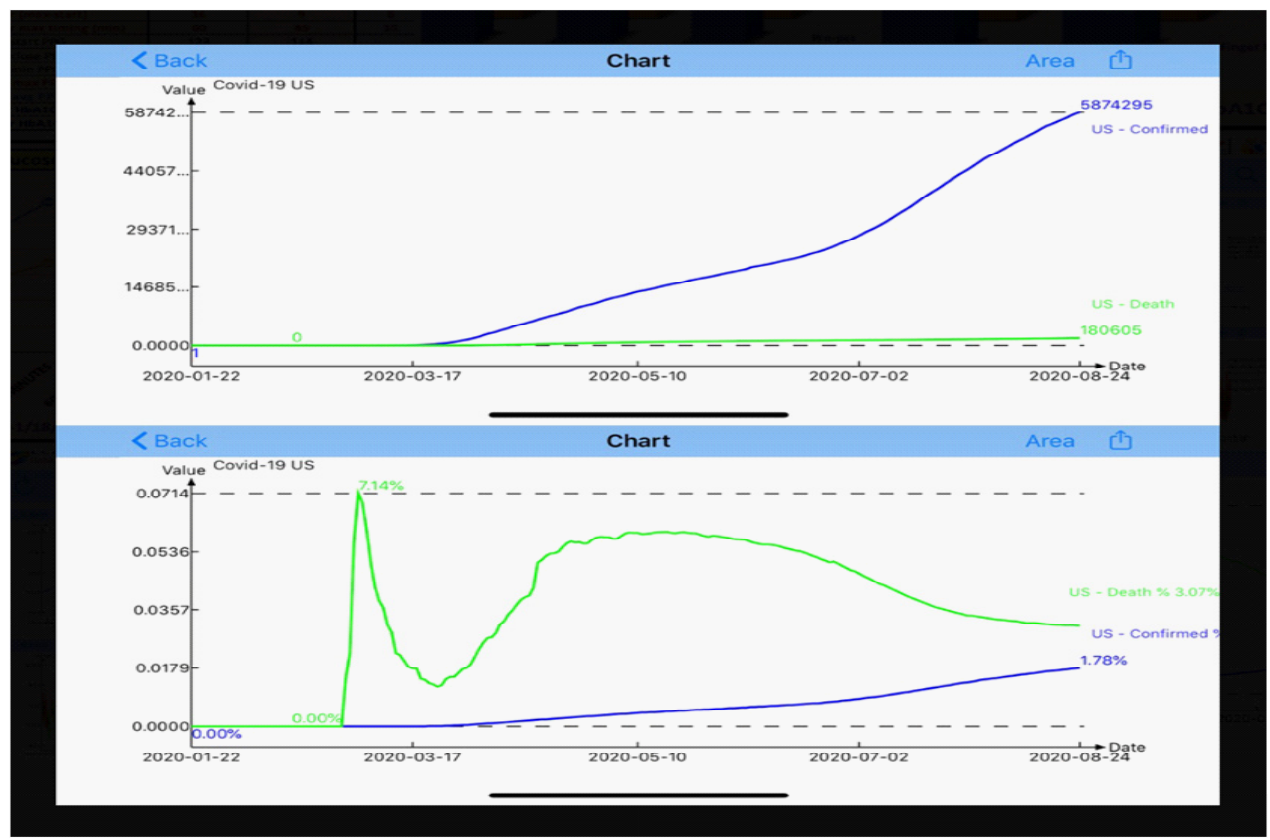

Fig2. COVID-19 history and status in USA (7/4/2020) 
A Postprandial Plasma Glucose (PPG) Comparison Study between Pre-COVID-19 and During COVID-19 Using GH-Method: Math-Physical Medicine (No. 317)

\section{Chronic Diseases and Health}

As indicated in the "Linkage among metabolism, immune system, and various diseases using $\mathrm{GH}$ Method: math-physical medicine (MPM)", the most effective defensive protection against COVID-19 is our immune system (Reference 4). The immune system is closely related to the overall metabolic conditions. We can safely say that metabolism and immunity are two sides of one coin. In order to strengthen our overall metabolism, we must manage our daily lifestyle to build up a strong and firm foundation over a long period of time (Figure 3).
In short, lifestyle is similar to the product quality and production capacity of an arsenal based on the overall educational, technological, and industrial power, whereas metabolism is similar to the effectiveness and destruction power of the weapons available to soldiers which are produced by an arsenal. Immunity is similar to the overall military strength of the armed defense force (assembly of soldiers with weapons), while diseases (chronic, cancer, and infections) are similar to an enemy's invasion force. Lastly, the study of death is similar to the investigation of outcomes of a war, which is the probability and rate of death.

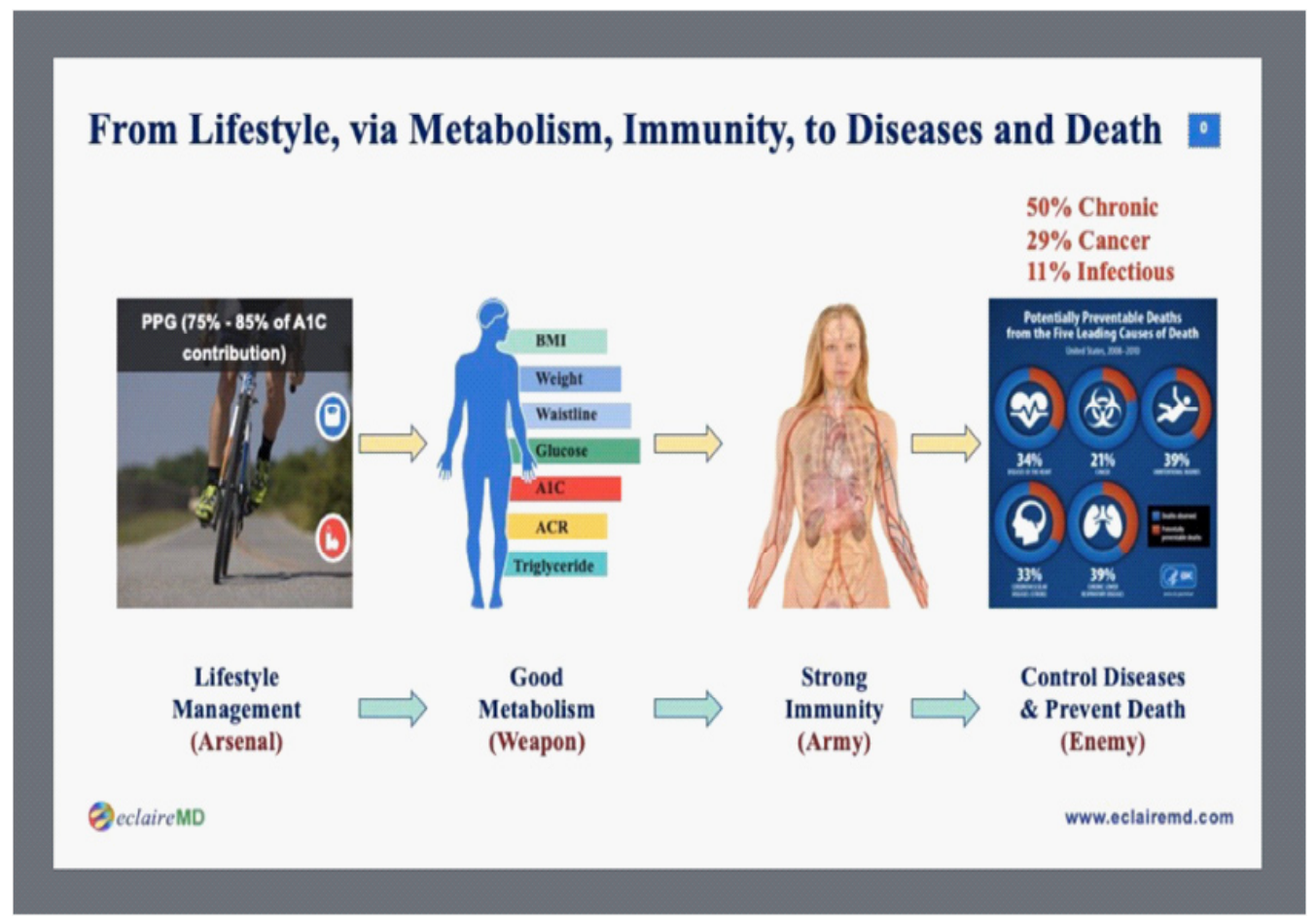

Fig3. Relationships among Lifestyle, Metabolism, Immunity, and Diseases

\section{RESULTS}

In Figure 4, it shows the background data table of glucose comparison between the periods of preCOVID-19 (5/5/2018 - 1/18/2018, 623 days with 1,934 meals) and COVID-19 (1/19/2020 - 8/24/2020, 218 days with 657 meals). This data table contains PPG data and HbA1C values. The PPG data group contains three datasets, finger-piercing tested PPG, CGM sensor measured PPG, and candlestick K-line converted PPG.

It is obvious that the COVID-19 period has a lower average Finger PPG value $(-6 \mathrm{mg} / \mathrm{dL})$ and also a lower sensor $P P G$ value $(-12 \mathrm{mg} / \mathrm{dL})$.
The sensor waveforms and K-line diagrams are illustrated for pre-COVID-19 and COVID-19, respectively (Figures $5 \& 6$ ).

The direct comparison between two synthesized curves with the average total of PPG curves at each time instant are depicted for pre-COVID-19 and COVID-19 (Figure 7).

It is evident that two glucose waveforms are similar in shape, with an extremely high correlation coefficient, along with the differences between these two curves at each time instant are quite close to each other about $12 \mathrm{mg} / \mathrm{dL}$ glucose difference. 
A Postprandial Plasma Glucose (PPG) Comparison Study between Pre-COVID-19 and During COVID-19 Using GH-Method: Math-Physical Medicine (No. 317)

\begin{tabular}{|l|c|c|c|}
\hline & $5 / 5 / 18-1 / 18 / 20$ & $1 / 19 / 20-8 / 24 / 20$ & \\
\hline & Pre-period & During-period & Difference \\
\hline Days & 623 & 218 & \\
\hline Meals & 1869 & 654 & \\
\hline Meals \& Snacks & 1934 & 657 & \\
\hline Finger PPG & 116 & 110 & 6 \\
\hline Carbs/Sgar (g) & 14.6 & 12.2 & \\
\hline Post-meal Walking (steps) & 4284 & 4290 & \\
\hline Sensor start PPG & 129 & 123 & \\
\hline Sensor close PPG & 131 & 120 & \\
\hline Sensor min PPG & 129 & 119 & \\
\hline Sensor max PPG & 145 & 132 & 13 \\
\hline Sensor avg PPG & 136 & 124 & 12 \\
\hline Sensor (max-start) & 16 & 9 & 6 \\
\hline Sensor max timing (min) & 60 & 45 & 15 \\
\hline K-line start PPG & 123 & 114 & \\
\hline K-line close PPG & 131 & 120 & \\
\hline K-line min PPG & 108 & 103 & \\
\hline K-line max PPG & 175 & 155 & 20 \\
\hline K-line avg PPG & 137 & 124 & 13 \\
\hline Finger HbA1C & 6.7 & 6.4 & 0.3 \\
\hline Sensor HbA1C & 6.8 & 6.4 & 0.4 \\
\hline
\end{tabular}

Fig4. Summary data table

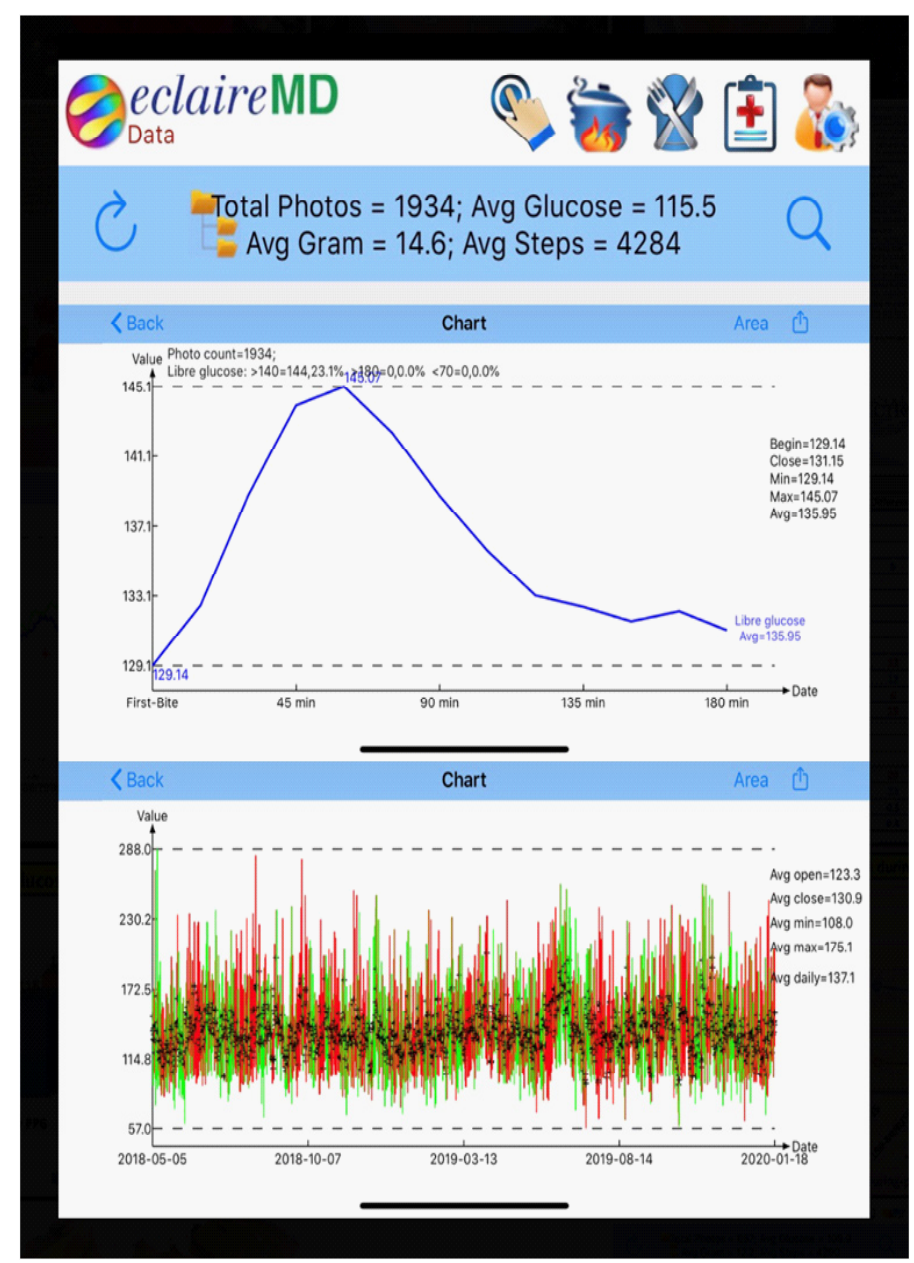

Fig5. PPG waveform and K-line glucoses (5/5/2018 - 1/18/2020) 


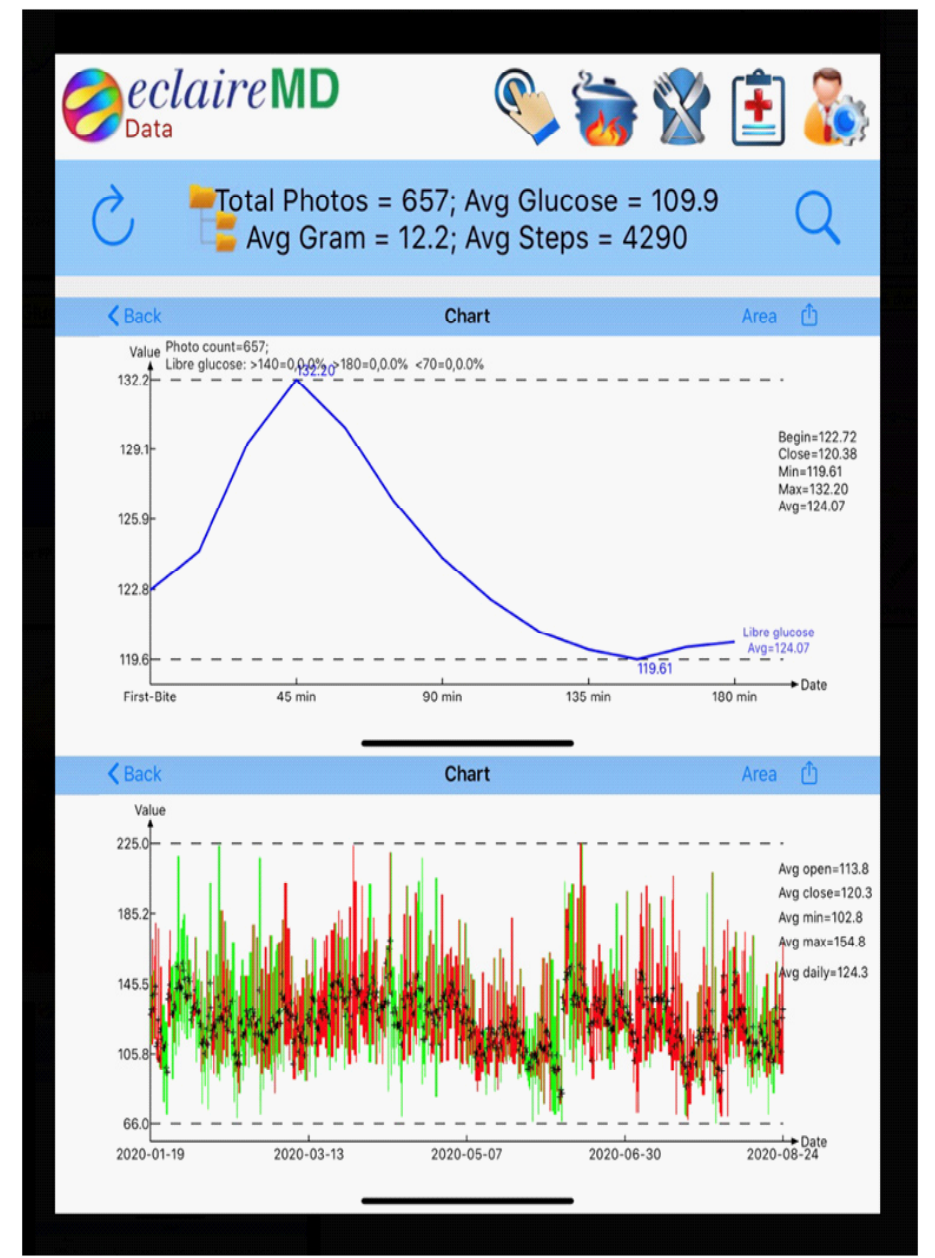

Fig6. PPG waveform and K-line glucoses (1/19/2020 - 8/24/2020)

The following list depicts several actual values from these two periods in the order of finger PPG value, sensor average PPG, carbs/sugar amount in grams, and post-meal walking steps:

Pre-COVID-19 Period (5/5/2018 - 1/18/2020)

$116 \mathrm{mg} / \mathrm{dL}, 136 \mathrm{mg} / \mathrm{dL}, 14.6$ grams, 4,284 steps

COVID-19 Period (1/19/202 - 8/24/2020)

$110 \mathrm{mg} / \mathrm{dL}, 124 \mathrm{mg} / \mathrm{dL}, 12.2$ grams, 4,290 steps

Here are some key findings regarding influential factors of glucose related to the author's lifestyle management during COVID-19 period:

(1) Carbs/sugar amount: The difference of 2.4 grams would contribute about 4 to $5 \mathrm{mg} / \mathrm{dL}$ glucose difference. This is mainly due to his home cooked meals without dining out during this timeframe. He also maintained high-quality protein with nutritional balanced diet.

(2) Exercise: This factor can be ignored since he sustained an almost equal level of post-meal walking steps during these two periods $(4,284$ steps for preCOVID-19 vs. 4,290 steps for COVID-19).

(3) Weather temperature: This factor can also be disregarded since both periods cover colder temperature in winter and warmer temperature in summer.

(4) No travel and jet lag during this timeframe.

(5) Stress-free life during this timeframe by focusing on his medical research work and avoiding the disturbance from news associated with current politics and COVID-19 developments.

(6) Sleep: He has maintained 7 to 8 hours of good quality sleep every night. 
A Postprandial Plasma Glucose (PPG) Comparison Study between Pre-COVID-19 and During COVID-19 Using GH-Method: Math-Physical Medicine (No. 317)

These 6 lifestyle details from above have kept his PPG within a healthy level without the involvement of medications.

glucose based during these two periods. The preCOVID-19 has HbA1C values of $6.7 \%$ to $6.8 \%$ and COVID-19 has HbA1C value of $6.4 \%$. Therefore, the In Figure 8, it shows his mathematically predicted $\mathrm{HbA1C}$ values for finger glucose based and sensor $\mathrm{HbA1C}$ difference between the two periods is $0.3 \%$ to $0.4 \%$ (Reference 8).

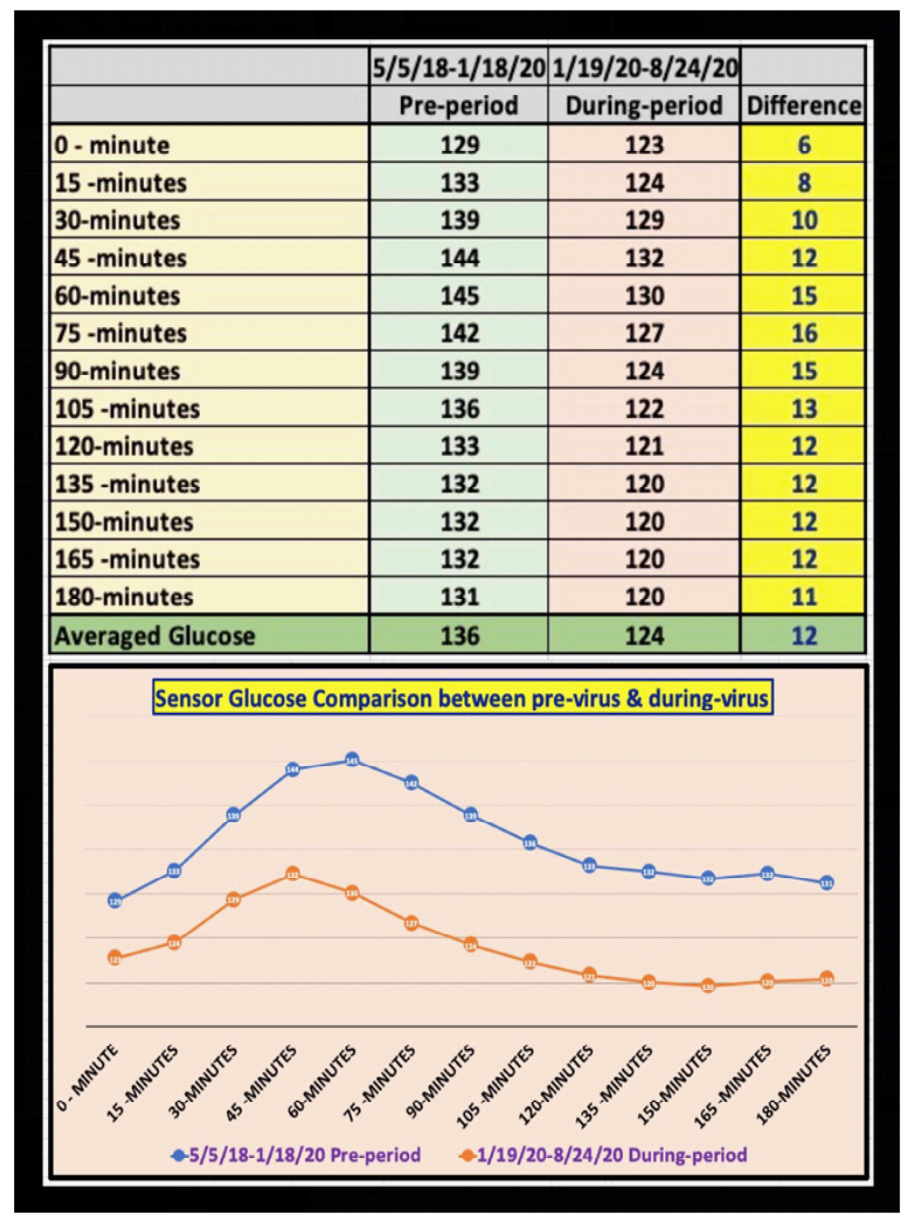

Fig7. Comparison of PPG waveforms between two periods

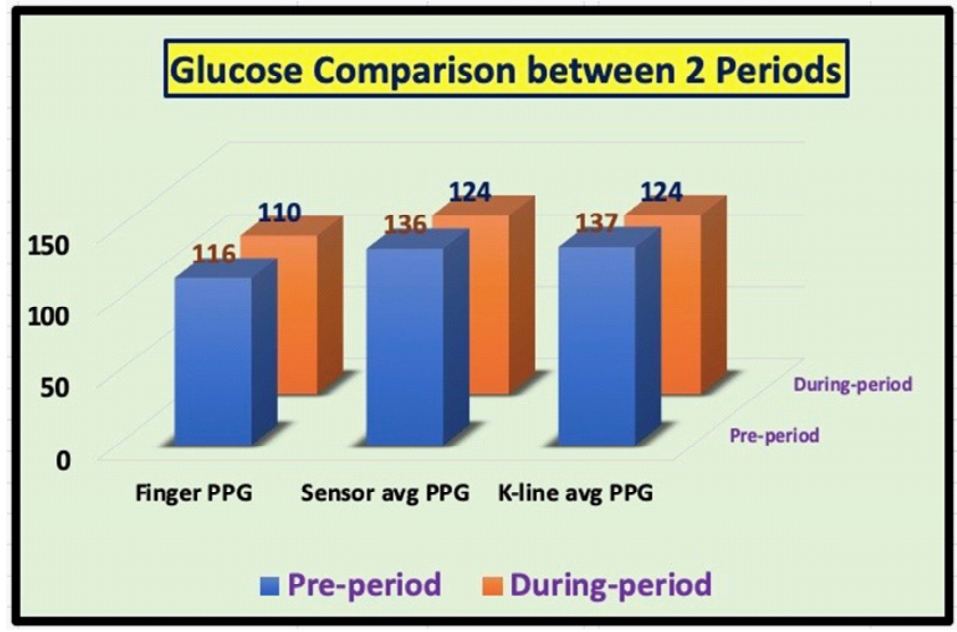

Fig8. Bar chart of 3 PPG (finger, sensor, and K-line) 


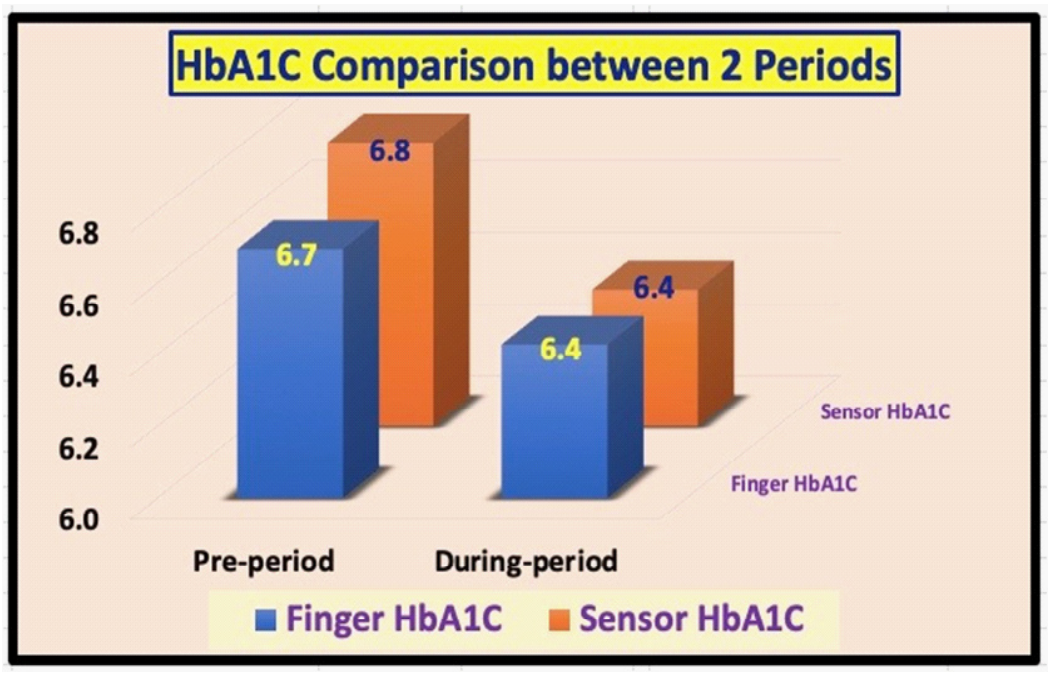

Fig9. Comparison of two periods' mathematically predicted HbA1C values from both finger based and sensor based

\section{ConCLUSIONS}

COVID-19 is more than $100 \mathrm{x}$ worse compared to the fatal respiratory illness known as severe acute respiratory syndrome or SARS that occurred in 2003, in regard to its spreading speed, fatality number, and emotional impact on the world population. People belonging to the "vulnerable" groups, such as the elderly with existing chronic diseases and history of complications require special consideration to their health conditions and lifestyle management during the COVID-19 period.

However, during this period, the author collected better results with his diabetes control in terms of both PPG and HbA1C values. The knowledge and experience he acquired in the past 10 years of medical research and his developed mathematical metabolism index model along with four diabetes prediction tools assisted him in many ways. As a result, he achieved a reduction of $-6 \mathrm{mg} / \mathrm{dL}$ for finger PPG, $-12 \mathrm{mg} / \mathrm{dL}$ for sensor PPG, $-13 \mathrm{mg} / \mathrm{dL}$ for K-line PPG, and $-0.3 \%$ to $-0.4 \%$ for $\mathrm{HbA} 1 \mathrm{C}$. In fact, he turned the COVID-19 crisis into his health advantage!

\section{REFERENCES}

[1] Hsu, Gerald C. (2020). eclaireMD Foundation, USA. "Biomedical research methodology based on GH-Method: math-physical medicine (No. 310)."
[2] Hsu, Gerald C. (2020). eclaireMD Foundation, USA, No. "Glucose trend pattern analysis and progressive behavior modification of a T2D patient using GH-Method: math-physical medicine (No. 305)."

[3] Dr. Joshua A. Davis. "COVID-19 at NYPH: What Are the Basics of the Disease, Symptoms and Risk Factors for Non-Critically Ill Patients?" New YorkPresbyterian Hospital, New York video, April 17, 2020, https://www.vumedi.com/video/covid19-at-nyph-what-are-the-basics-of-the-diseasesymptoms-and-risk-factors-for-non-criticallyill/.

[4] Gerald C. Hsu. (2020). eclaireMD Foundation, USA. No. 235: "Linkage among metabolism, immune system, and various diseases using $\mathrm{GH}-$ Method: math-physical medicine (No. 235)."

[5] Gerald C. Hsu. (2020). eclaireMD Foundation, USA. "Building up fundamental strength to fight against COVID-19 for patients with chronic diseases and complications (No. 253)."

[6] Gerald C. Hsu. (2019). eclaireMD Foundation, USA. "Using Candlestick Charting Techniques to Investigate Glucose Behaviors via GH-Method: Math-Physical Medicine (No. 076)" 
A Postprandial Plasma Glucose (PPG) Comparison Study between Pre-COVID-19 and During COVID-19 Using GH-Method: Math-Physical Medicine (No. 317)

[7] Gerald C. Hsu. (2020). eclaireMD Foundation, USA. "Comparison study of PPG characteristics [8] Gerald C. Hsu. (2020). eclaireMD Foundation, from candlestick model using GH-Method: MathPhysical Medicine (No. 261)." USA. "A Case Study on the Prediction of A1C Variances over Seven Periods with guidelines Using GH-Method: math-physical medicine (No. 262).”

Citation: Gerald C. Hsu. A Postprandial Plasma Glucose (PPG) Comparison Study between Pre-COVID-19 and During COVID-19 Using GH-Method: Math-Physical Medicine (No. 317). Open Journal of Geriatrics. 2020; 3(2): 01-09.

Copyright: (C) 2020 Gerald C. Hsu. This is an open access article distributed under the Creative Commons Attribution License, which permits unrestricted use, distribution, and reproduction in any medium, provided the original work is properly cited. 